\title{
Twelfth international symposium on biological and environmental reference materials (BERM 12)
}

\author{
Mike Sargent
}

Published online: 12 March 2010

(C) UKCrown: LGC Limited 2010

The 12th International Symposium on Biological and Environmental Reference Materials, which was held at Keble College, Oxford, UK, on 7-10 July 2009, continued a series which began in 1983 and has been held on a regular basis since then. The event originated as an informal gathering of interested scientists, particularly those working in Europe and the USA between which the meetings alternated every 2 or 3 years. More recently, BERM has been steered by a permanent committee comprising many of the major reference material producers and other key players. Asia has seen rapidly increasing interest in the field and the BERM 11 meeting was held in Japan. Hence, BERM 12 was a truly global forum which addressed the development of biological and environmental reference materials and their use in the calibration, validation and quality assurance of analytical measurements.

As with previous symposia, the scientific programme for BERM 12 encouraged discussion of issues ranging widely from novel methods for the manufacture and certification of reference materials to topics such as quality assurance and international harmonization. This special issue of Analytical and Bioanalytical Chemistry focuses attention on some of the scientific developments described at BERM 12. Hence, we have a number of contributions describing novel analytical measurements in areas of current interest such as laboratory medicine, forensic science, food and nutrition, and environmental quality. Many of these papers were contributed by national measurement institutes from around the world, but the BERM symposia were conceived as a way of promoting international collaboration on reference materials amongst all interested parties, including academic researchers and industrial users of reference materials. An insight into the role of the BERM symposia in the development of reference materials for food and nutrition is given in the paper by Wayne Wolf, who was one of the organizers of the first meeting. I hope that readers from all types of organizations will be encouraged to attend the next BERM meeting in 2012 and join in our ultimate goal of improving the reliability of analytical data.

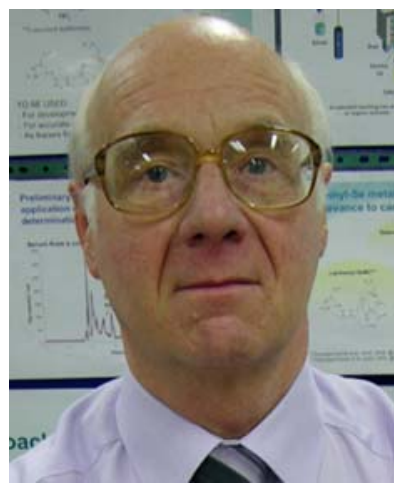

\section{Mike Sargent}

is an analytical chemist by profession, with 40 years' experience of research and development, laboratory and project management, analytical quality and reference materials. His current post at LGC Ltd, a private company formed from the UK's Laboratory of the Government Chemist, is that of Chief Chemical Metrologist. He has played a leading role in developing and gaining acceptance for the UK's chemical metrology infrastructure and in the development of international chemical metrology. Mike Sargent represents the UK at MetChem,

the chemistry committee of EURAMET, and at the Consultative Committee on Amount of Substance (CCQM) of the International Committee of Weights and Measures. He has chaired the Inorganic Analysis Working Group of the CCQM since 1997. He has authored or contributed to an extensive range of scientific books and papers.

\section{Sargent $(\bowtie)$}

LGC,

Queen's Road,

Teddington TW11 0LY, UK

e-mail: mike.sargent@1gc.co.uk 